УДК 332.146 .2

\title{
ПОНЯТИЕ И ОСНОВНЫЕ ХАРАКТЕРИСТИКИ ТЕХНОЛОГИЧЕСКИХ ПЛАТФОРМ В РОССИИ
}

\author{
(C) 2012 г. A. A. Карпухин
}

\section{Институт проблем управления РАН, г. Москва}

Настоящая статья посвящена технологическим платформам в России. Технологическая платформа является новым явлением в экономике и предполагает объединение государства, бизнеса, науки и общества, в иелях экономико-социалистического развития и совершения прорыва в области науки и экономики. Формирование технологических платформ в России только началось, но, к сожалению, пока не сформировалась научная и эмпирическая база содержания и формы технологических платформ. В этом смысле рассматриваемая статья отвечает на ряд научных вопросов.

Ключевые слова: технологическая платформа; государственно-частное партнерство; экономическое развитие; наука и бизнес.

In the article author presents an idea of the technology platforms by the examples from Russian economy. Technology platform is a new phenomenon in the economy, which appears as the co-operation between the government, business, science and society for attaining the socialist economic development objects, and making a breakthrough in the field of science and economics. The process of technology platforms forming in Russia has just started, but, unfortunately, has not formed a scientific and empirical basis of content and form of technological platforms. In this sense, the article in question is responsible for a number of scientific issues.

Key words: technology platform; public private partnerships; economic development; science and business.

В последние несколько лет поисков дальнейших путей модернизации отечественной экономики, а также повышения экономической эффективности привели Правительство РФ к идее создания так называемых технологических платформ. При этом руководство страны определило приоритеты модернизации - это энергоэффективность и энергосбережение, ядерные, космические, медицинские и информационные технологии.

Технологические платформы есть механизм развития, который на основе государственно-частного партнерства обеспечивает выработку и реализацию стратегических приоритетов в масштабах отдельных секторов экономики. Механизм этот уже достаточно хорошо апробирован в Европе. Например, в России согласно Решению Правительственной комиссии по высоким технологиям и ин-

новациям от 21.02.2012 г. в Перечень технологических платформ входит порядка тридцати, среди них: технологическая платформа «Медицина будущего», «Биоэнергетика», «Развитие сельскохозяйственных технологий», «Управляемый термоядерный синтез» и многие другие [1].

Прежде всего, модернизация, и как одно из ее проявлений - технологическая платформа имеют краеугольным камнем эффективность. Уже с самого начала формирования технологических проектов все в них работает на эффективность: и тщательный анализ рыночного потенциала технологий с привлечением экспертного сообщества, и общее видение заинтересованными сторонами (государство, бизнес и потребители) рыночных перспектив проекта, и мобилизация общественных и частных источников финансирова- 
ния. А главное - сопровождение проекта со стороны науки и бизнеса на всем протяжении цикла разработки, производства и сбыта инновационной продукции.

Что представляет собой технологическая платформа? Согласно европейскому опыту, «Европейские технологические платформы» - это термин, предложенный Еврокомис-сией для обозначения тематических направлений, в рамках которых сформулированы или будут сформулированы научно-технические приоритеты в 7-й Рамочной программе Евросоюза. В рамках именно этих направлений предполагается выделение существенных объемов финансирования для проведения различных научно-исследовательских работ, непосредственно связанных с их практической реализацией предприятиями малого и среднего бизнеса и промышленностью. Особенностью технологических платформ в Евросоюзе является их формирование на основе анализа спроса потенциальных потребителей и рынка передовых технологий, потребностей производства и т. д., что предполагает проведение научно-исследовательских работ для достижения целей и стратегий устойчивого и ресурсно-возобновляемого развития современного общества.

Европейская Концепция технологических платформ позволяет обеспечить:

- выбор стратегических научных направлений;

— анализ рыночного потенциала технологий;

- учет точек зрения всех заинтересованных сторон: государства, промышленности, научного сообщества, контролирующих органов, пользователей и потребителей;

- активное вовлечение всех стран Европейского союза;

- мобилизацию общественных и частных источников финансирования.

Технологические платформы были созданы на паевой основе за счет объединения интеллектуальных и финансовых ресурсов Евросоюза и крупнейших европейских промышленных производителей и финансовых ресурсов с целью активизации научных исследований, необходимых для удовлетворения потребностей современного промышленного производства.
Как правило, формирование технологической платформы инициируется крупным европейским бизнесом, различного рода отраслевыми объединениями промышленных производителей и т. п., представители которых входят в так называемую Группу высшего уровня. Для разработки технологической инициаторы платформы образуют Совещательный комитет, в который входят представители Еврокомиссии, научного сообщества, мелкого и среднего бизнеса, организации и объединения потребителей, различные некоммерческий государственные объединения и пр. Одновременно формируются Национальные группы поддержки из представителей заинтересованных стран и регионов. Для разработки научной составляющей технологической платформы создается Научный совет, куда входят ведущие эксперты по данной проблеме, представляющие академическую и прикладную науки [2].

Основными задачами создаваемых европейских технологических платформ являются:

- пропаганда и продвижение формируемых технологических платформ, их целей и задач, соответствующих технологических платформ в европейском обществе и в структурах Евросоюза;

- разработка стратегического плана исследований - основного документа, который обосновывает, в каких направлениях, почему, с какими целями и в какие сроки необходимо проводить исследования в рамках данной технологической платформы;

- разработка плана внедрения технологической платформы [3].

По нашему мнению, технологическая платформа представляет собой коммуникационный инструмент, направленный на активизацию усилий по созданию: перспективных коммерческих технологий новых продуктов/ услуг, на привлечение дополнительных ресурсов для проведения исследований и разработок на основе участия всех заинтересованных сторон (государства, бизнеса и науки), совершенствования нормативно-правовой базы в области научно-технологического, инновационного развития.

Как было сказано, субъектами технологической платформы являются государство, 
бизнес и наука. Государство участвует в лице своих органов или специально созданных учреждений, наделенных определенной компетенцией. Бизнес участвует также в лице своих полномочных органов управления (учредителей/акционеров, совета директоров, правления, генерального директора и пр.). Наука представлена различными объединениями, как-то: исследовательскими институтами, лабораториями, сообществами, союзами и т. п. Взаимодействие субъектов технологической платформы призвано обеспечивать выработку и реализацию долгосрочных (стратегических) приоритетов в масштабах определенных секторов экономики в целях их инновационно-прорывного развития и экономики в целом [4]. Рассматриваемое взаимодействие может реализовываться также в рамках государственного частного партнерства.

Взаимодействие субъектов технологической платформы приносит определенные выгоды. Потенциальные выгоды государства:

- определение средне- и долгосрочных приоритетов научно-технологической политики;

- концентрация на определенных направлениях модернизации экономики частных и государственных ресурсов;

— координация НИОКР, финансируемых за счет бюджетных средств;

- выявление направлений совершенствования регулирования, в том числе отраслевого;

— улучшение условий для распространения передовых технологий;

- повышений эффективности крупных государственных компаний;

- повышение бюджетных расходов.

При этом бизнес получает следующие выгоды [5]:

- улучшение среды для инноваций, стимулирование спроса на инновационную продукцию;

- улучшение качества подготовки кадров с учетом необходимых технологических компетенций;

- финансовая поддержка реализации инновационных проектов;

- новые возможности для технологической модернизации и расширения горизонта планирования;
- возможности для выпуска принципиально новой продукции;

- расширение возможностей для выбора партнеров, селекция контрагентов;

- политическая поддержка на мировых рынках, возможности формирования международных альянсов по направлениям, характеризующимися высокими рисками и требующих объединения ресурсов;

- поддержка и внимание общественности, расширение спроса населения на инновационные товары (работы, услуги).

Преимуществами науки от участия в технологических платформах являются:

- привлечение бизнеса к партнерству с научными организациями, демонстрационный эффект для бизнеса, расширение спроса для бизнеса на НИОКР;

- расширение компетенций, представляющих интерес для бизнеса (обучение, инжиниринг, дизайн, долгосрочное планирование);

- включение малых фирм, созданных научно-образовательными учреждениями, в сети субподряда; науки;

- заполнение «провалов» прикладной

— формирование новых коопераций в научной сфере;

- формирование центров научной компетенции, в том числе на уровне подразделений научных и научно-образовательных организаций;

- формирование потенциала для реализации сложных проектов с множеством участников.

Для участия субъектов в технологической платформе необходимо разработать план участия, а затем наступает его реализация. В рамках разработки плана рекомендуется выполнить следующие подготовительные работы:

1. Выявление профильных технологических платформ из числа технологических платформ, включенных в перечень, утвержденный Правительственной комиссией по высоким технологиям и инновациям. Оценку соответствия направлений деятельности технологических платформ приоритетным для компании направлениям технологического развития рекомендуется осуществлять на ос- 
нове проектов реализации технологических платформ, а также их стратегических программ исследований.

2. Определение направлений, в том числе исследований и разработок, коммерциализации их результатов, подготовки и повышения квалификации научных и инженерно-технических кадров, по которым компания заинтересована координировать свои действия и/или осуществлять кооперацию с другими участниками профильных технологических платформ.

3. Определение целей и задач участия компании в деятельности профильных технологических платформ, в том числе исходя из целей и задач реализации программы инновационного развития компании.

Разработка плана в технологической платформе осуществляется в следующем порядке:

1) Определение исполнителей, ответственных за разработку плана. Подготовка графика работ по разработке плана.

2) Разработка проекта плана. Обеспечение возможности ознакомления с проектом плана для всех заинтересованных участников профильных технологических платформ (размещение проекта на интернет-странице, где размещен паспорт программы инновационного развития, на интернет-странице платформы, его рассылка по электронной почте и т. п.).

3) Информирование профильных технологических платформ об основных направлениях исследований и разработок, предусмотренных к реализации в рамках программы инновационного развития компании, обеспечение возможности ознакомления с программой инновационного развития или с паспортом программы для всех заинтересованных участников профильных технологических платформ (размещение на интернет-странице платформы, его рассылка по электронной почте и т. п.).

4) Сбор предложений профильных технологических платформ по доработке проекта плана. Доработка проекта плана с учетом предложений профильных технологических платформ.

5) Проведение совместных совещаний с участием представителей компании и профильных технологических платформ для об- суждения и согласования проекта плана.

6) Информирование профильных технологических платформ об итогах разработки проекта плана. Обеспечение возможности ознакомления с доработанным проектом плана для профильных технологических платформ.

7) Утверждение плана по участию акционерного общества с государственным участием (государственной корпорации, федерального государственного унитарного предприятия), реализующего программу инновационного развития, в деятельности технологических платформ по приоритетным для компании направлениям технологического развития.

8) Мониторинг хода реализации плана.

Технологическая платформа имеет координатора - организацию, которая осуществляет организационное, информационное обеспечение взаимодействия субъектов технологической платформы. Например, в рамках технологической платформы «Медицина будущего» координатором является Государственной образовательное учреждение высшего профессионального образования «Сибирский государственный медицинский университет», «Биоиндустрия и биоресурсы - БиоТех2030» координатор - ОАО «РТ-Биотехпром».

В ходе реализации деятельности технологических платформ осуществляется:

- разработка стратегической программы исследований, предусматривающей определение средне- и долгосрочных приоритетов в проведении исследований и разработок, выстраиваемых механизмов научно-производственной кооперации;

- формирование программ обучения, определение направлений и принципов развития стандартов, системы сертификации, реализации мер по развитию инновационной инфраструктуры;

- разработка программы по внедрению и распространению передовых технологий в соответствующих секторах российской экономики, определяющей различные механизмы и источники финансирования, обязательства участников технологической платформы;

- создание организационной структуры, обеспечивающей необходимые условия реализации взаимодействия между предприяти- 
ями, научными и образовательными организациями.

\section{Литература}

1. Программа развития инновационной инфраструктуры: технологические платформы [Электронный ресурс] / Высшая школа экономики - Национальный исследовательский университет. - Режим доступа: http:// www.hse.ru/org/hse/aup/innovat/23926779/02, свободный. - Загл. с экрана.

2. Применение технологических платформ в России [Электронный ресурс] / Федеральный портал Protown.ru. - Режим доступа: http://www.protown.ru/information/ hide/4502.html, свободный. - Загл. с экрана.

3. Технологические платформы: нацио- нальная программная платформа [Электронный ресурс] / Высшая школа экономики Национальный исследовательский университет. - Режим доступа: http://www.hse.ru/ org/hse/tp/info_com_npp, свободный. - Загл. с экрана.

4. Санкт-Петербургский государственный технологический институт (технический университет) [Электронный ресурс] / Официальный сайт. - Режим доступа: http:// technolog.edu.ru/nich/pdf, свободный. - Загл. с экрана.

5. Шадрин A. E. О формировании технологических платформ [Электронный ресурс] / Московская школа управления «Сколково». - Режим доступа: http://www.skolkovo. $\mathrm{ru} /$ public/media/documents/rd/shadrin.pdf, свободный. - Загл. с экрана.

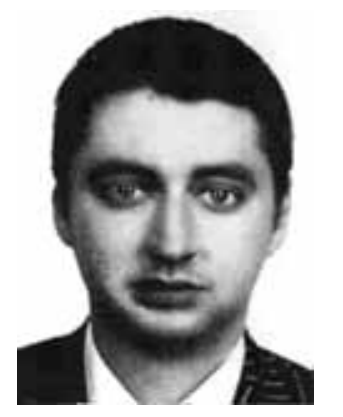

Антон Анатольевич Карпухин - соискатель степени кандидата экономических наук Института проблем управления Российской академии наук.

Anton Anatolievich Karpukhin - competitor for Candidate's degree in Economy at the Russian Academy of Sciences' Institute of Control Scieneces.

117997, Москва, ул. Профсоюзная, д. 65, ИПУ РАН

65 Profsoyuznaya st., ICS RAS, 117997, Moscow, Russia

Тел.: +7 (495) 334-89-10; факс: +7 (495) 334-93-40, +7 (499) 234-64-26;

e-mail: bell44@rambler.ru,snv@ipu.ru 